\title{
Auto-imagem do cirurgião-dentista: um estudo baseado em desenhos de alunos de graduação
}

\author{
Objetivou-se analisar as representações da auto-imagem \\ profissional de graduandos com o intuito de avaliar o grau \\ de assimilação de certas posturas profissionais transmitidas \\ pelo currículo odontológico da UBC.
} Sandra Pacca*, Luciana Corrêa*, Márcia Motta**

* Professoras do Curso de Odontologia da Universidade Braz Cubas - Mogi das Cruzes.

** Ex-coordenadora do Curso de Odontologia da Universidade Braz Cubas - Mogi das Cruzes.

\section{RESUMO}

O objetivo deste trabalho consiste em analisar as representações da auto-imagem profissional dos estudantes do Curso de Odontologia da Universidade Braz Cubas (UBC). Foi solicitado aos alunos ( $1^{\circ}$ semestre e $7^{\circ} / 8^{o}$ semestres) que confeccionassem um desenho representativo do perfil profissional que almejavam, com o intuito de detectar indicadores que pudessem nortear o grau de assimilação de certas posturas profissionais transmitidas pelo currículo odontológico da UBC. Os desenhos foram classificados e quantificados segundo os seguintes critérios: cenário, instrumentais utilizados, material odontológico, vestuário, paciente, normas de biossegurança, explicitação de emoções e presença de vocábulos. Nos alunos de $7^{\circ} / 8^{\circ}$ semestres, ficou evidente a incorporação de conceitos de prevenção; a maioria ( $1^{\circ}$ e $7^{\circ} / 8^{\circ}$ semestres) representou-se como profissionais de consultórios particulares bem-sucedidos e tecnologicamente bem equipados. O paciente raramente esteve representado nos desenhos; quando presente, compunha uma relação impessoal com o profissional. Conclui-se que o aluno da UBC está assimilando atitudes e iniciativas de prevenção. Porém, apesar de todos os esforços, o caráter humanístico da profissão carece maior desenvolvimento.

\section{DESCRITORES}

Educação em Odontologia. Estudantes de Odontologia. Currículo. Prevenção primária, educação.

$\mathbf{N}$ o projeto pedagógico da UBC, está explícita a intenção de se formar um profissional generalista, com ênfase em prevenção e com base humanista. Em 2001, foi criada a disciplina "Estágio E" que tinha, dentre outros objetivos, avaliar a eficiência das metodologias pedagógicas utilizadas pelo corpo docente para se atingirem os objetivos do projeto pedagógico. Nessa disciplina, foram trabalhados conceitos que envolviam a relação paciente-profissional, principalmente em relação à imagem que o paciente tem do cirurgião-dentista. Para tal, utilizaram-se recursos de Psicologia e de Semiótica visual, esclarecendo ao aluno pelo menos duas maneiras diferentes de tratar o mesmo tema: uma sob a ótica das relações humanas e outra sob a ótica lingüística e da comunicação.

Para ilustrar algumas dessas aulas, foram projetadas imagens com pelo menos duas formas de interpretação para se atingir uma informação da realidade. A projeção de obras artísticas foi a estratégia de abordagem adotada, sendo utilizados alguns trabalhos de Maurits Cornelis Escher (1898-1972), como "Plane Filling II" (1950) e "Circle Limit IV" (1960) (CORDON ART, 2003). Com essas gravuras, o aluno 


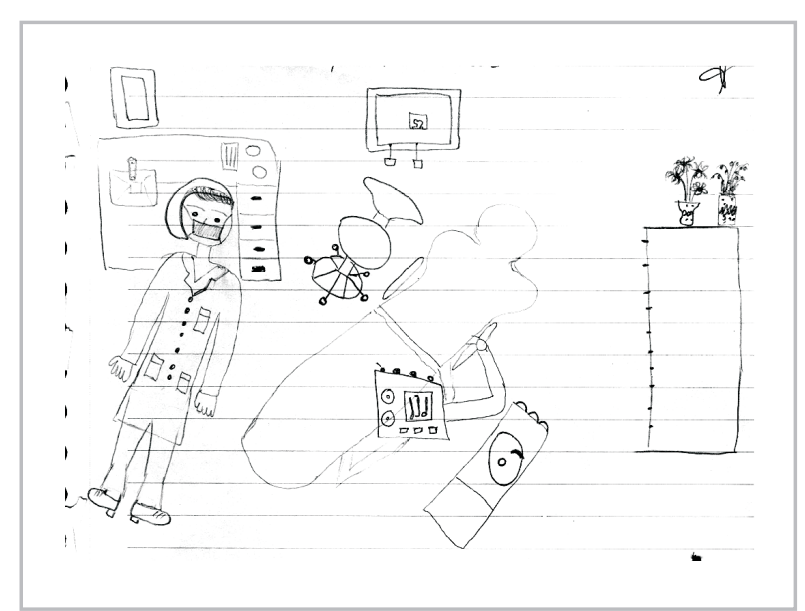

Figura 1 - Exemplo de aplicação da metodologia. Desenho contendo cenário do tipo consultório odontológico, cirurgião-dentista com vestuário adequado (havendo equipamentos de proteção individual) e ausência do paciente (confeccionado por aluna do $8^{\circ}$ semestre).

era impelido a interpretar as imagens dúbias criadas por Escher, bem como compor um texto coerente com as informações obtidas das ilustrações.

Uma das atividades propostas nessa disciplina foi que os alunos fizessem um desenho de como eles se vêem como profissionais. O intuito foi avaliar qual objetivo do projeto pedagógico estava sendo assimilado, a ponto de ser transferido para os desenhos. $\mathrm{O}$ presente trabalho ilustra essa experiência.

\section{MATERIAL E MÉTODOS}

Foi solicitado aos alunos de $7^{\circ}$ e $8^{\circ}$ semestres, matriculados na disciplina Estágio $\mathrm{E}$, que confeccionassem desenhos ilustrando a sua imagem profissional futura como cirurgiões-dentistas. Essa solicitação também foi feita para alunos de $1^{\circ}$ semestre na disciplina de Língua Portuguesa, para se ter uma referência da forma como os alunos ingressantes vêem a profissão em relação a alunos formandos. Antes de fazerem os desenhos, foram apresentados textos aos alunos relativos à relação paciente-profissional, à imagem que os pacientes fazem dos dentistas e à importância social dessas interpretações. Em seguida, os estudantes fizeram os desenhos com os recursos que dispunham no momento, em geral lápis, folha de caderno e caneta.

Os desenhos dos alunos foram classificados e quantificados pelos dois professores da disciplina com base nos seguintes critérios (Figura 1): cenário (ausência ou presença de consultório odontológico), material e instrumental odontológico (relacionados a tratamento curativo e ou preventivo), vestuário (refletindo normas de biossegurança ou não), paciente (presença ou ausência), explicitação

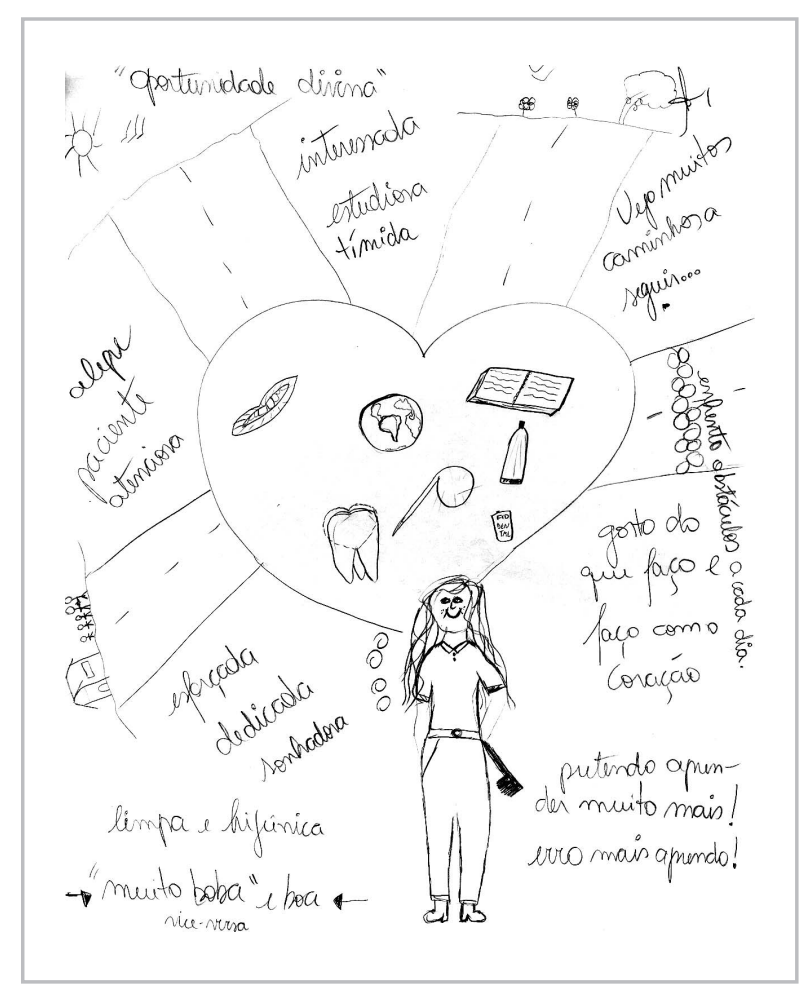

Figura 2 - Desenho de aluna de $7^{\circ}$ semestre mostrando os vocábulos de otimismo e de adjetivos pessoais que refletem no espírito profissional.

de emoções (face tristonha, alegre ou indiferente) e presença de vocábulos (palavras de otimismo, pessimismo ou indiferentes). Esses critérios foram determinados tendo-se como referência os objetivos do projeto pedagógico da UBC.

\section{RESULTADOS}

Com relação ao cenário, $67 \%$ dos alunos de $1^{\circ}$ semestre não retrataram qualquer tipo de cenário, enquanto $39 \%$ dos alunos de $7^{\circ} / 8^{\circ}$ semestres desenharam o consultório odontológico, este bem equipado e com alta tecnologia.

Foram citados vocábulos que indicam otimismo em relação à profissão e qualidades pessoais que interferem na identidade profissional, tais como: "responsável”, “organizada”, "dedicada”, “detalhista”, "alegre", "paciente" (Figura 2).

O paciente esteve ausente na maioria dos desenhos dos alunos de $7^{\circ} / 8^{\circ}$ semestres. O mesmo sucedeu com os alunos de $1^{\circ}$ semestre, porém com menor freqüência (Gráfico 1).

Quando o material odontológico esteve representado, observou-se que os alunos de $7^{\circ} / 8^{\circ}$ semestres se preocuparam em ilustrar materiais de prevenção, o que não se observou com os alunos de $1^{\circ}$ semestre (Gráfico 2).

Já o vestuário foi considerado inadequado com 


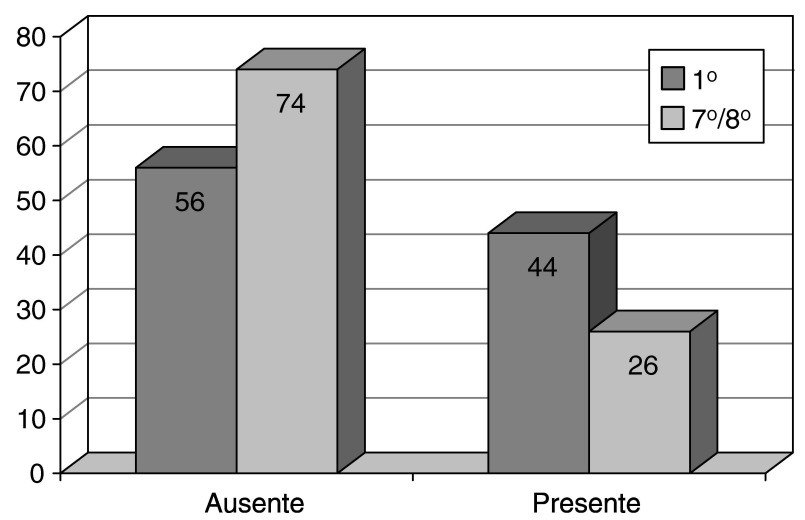

Gráfico 1 - Freqüência (\%) de desenhos dos alunos de $1^{\circ}$ e $7^{\circ} / 8^{\circ}$ semestres em relação à ausência ou à presença do paciente.

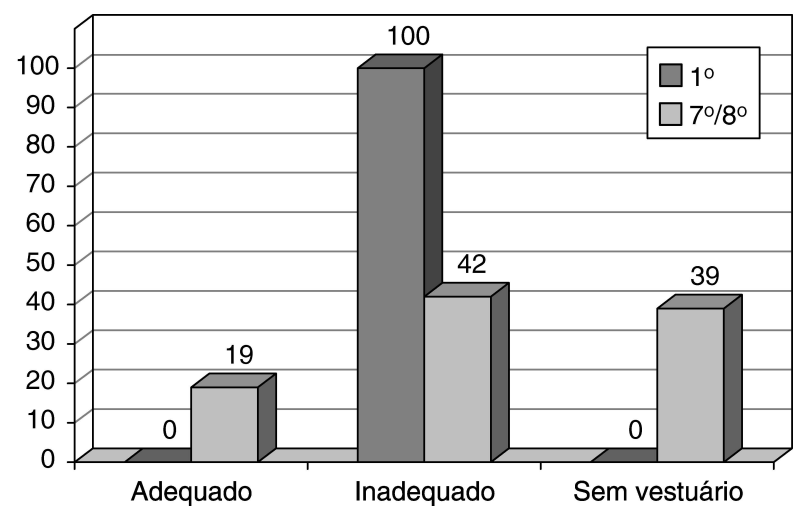

Gráfico 3 - Freqüência (\%) de desenhos dos alunos de $1^{\circ}$ e $7^{\circ} / 8^{\circ}$ semestres em relação ao vestuário. O item "sem vestuário" diz respeito à vestimenta não específica de Odontologia.

relação às normas de biossegurança em todos os desenhos dos alunos de $1^{\circ}$ semestre. Os alunos de $7^{\circ}$ / $8^{\circ}$ semestres também desenharam, com uma porcentagem significativa, vestuários inadequados, porém alguns fizeram um retrato fiel dos equipamentos de proteção individual (EPIs) (Gráfico 3).

As Figuras 2 e 3 ilustram algumas dessas situações, constituindo exemplos de desenhos de um aluno de $1^{\circ}$ semestre e outro de $7^{\circ}$ semestre, respectivamente.

\section{DIscussão}

Verificar o cumprimento de objetivos de um projeto pedagógico constitui tarefa complexa, em que se devem examinar vários aspectos do sistema educacional, tais como currículo, avaliação e aprendizado. Neste trabalho, procurou-se identificar alguns indicadores que sinalizassem um possível aprendizado de conceitos envolvendo biossegurança e prevenção e a vinculação desses conceitos à profissão odontológica. Para tal, optou-se por uma metodologia de pes-

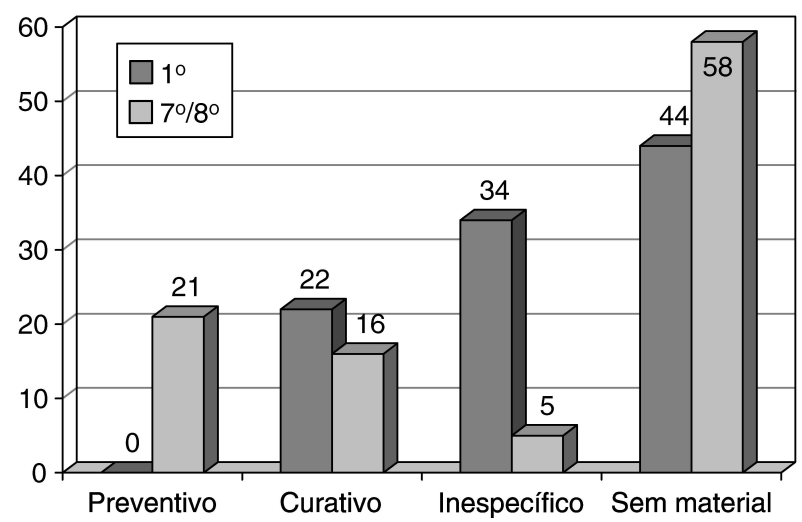

Gráfico 2 - Freqüência (\%) de desenhos dos alunos de $1^{\circ}$ e $7^{\circ} / 8^{\circ}$ semestres em relação ao tipo de material e instrumental odontológico ilustrado. O material dito "inespecífico” envolveu, em geral, material de escritório.

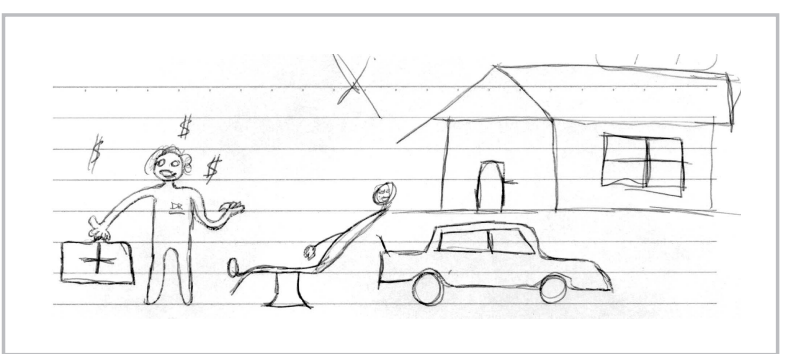

Figura 3 - Desenho de aluno de $1^{\circ}$ semestre indicando as aspirações de riqueza e status social com a profissão odontológica.

quisa em que se trabalhou o aspecto lúdico e a espontaneidade dos alunos (MCLEAN et al., 2003; COX, 2001; CAMPOS, 2002), sem qualquer processo indutivo na coleta dos dados. O que se procurou fazer foi introduzir fundamentos da relação paciente-profissional baseado nas imagens sociais recíprocas. Com isso, procurava-se avivar no aluno o aspecto humanista, tão almejado no projeto pedagógico da UBC.

Um dos indícios desse aspecto seria flagrar, nos desenhos, o paciente e verificar como este é retratado. Observou-se que poucos alunos, principalmente os do $7^{\circ} / 8^{\circ}$, desenharam o paciente (Gráfico 1), preocupando-se mais com aspectos técnicos e o status profissional. Essa tendência já foi constatada em outros trabalhos envolvendo a coleta de dados sobre a profissão odontológica com alunos de graduação, como os de BotTi, SAntos, 1986; Cruz, Silva, 1996; HALlissey et al., 2000; CHAMBERS, 2001 e SKelly, Fleming, 2002. Ao mesmo tempo, os alunos de $7^{\circ} / 8^{\circ}$ semestres não focalizaram o paciente com a mesma freqüência que os alunos de $1^{\circ}$ semestre, o que pode indicar falhas no processo de abordagem da relação profissional-paciente durante o curso.

Apesar da grande freqüência de desenhos sem alusão ao material e instrumental odontológico, ob- 
serva-se que os alunos de $7^{\circ} / 8^{\circ}$ semestres se preocuparam em ilustrar materiais de prevenção (Gráfico 2), os quais foram o flúor, o fio dental e a escova de dentes. Já os alunos de 1ํㅗㄹ semestre não se preocuparam com os aspectos preventivos na mesma intensidade que os alunos de $7^{\circ} / 8^{\circ}$ semestres, o que pode constituir um indicador do cumprimento dos objetivos do projeto pedagógico de se formar um profissional generalista com ênfase em prevenção.

Todos os alunos do $1^{\circ}$ semestre desenharam o dentista sem nenhum tipo de equipamento de biossegurança, o que não se observou com os alunos de $7^{\circ} / 8^{\circ}$ semestres. Essa diferença provavelmente ocorreu porque os alunos de $1^{\circ}$ semestre ainda não entraram em contato com esses princípios.

\section{Conclusóes}

Houve diferenças de representação da profissão odontológica entre os alunos de $1^{\circ}$ e $7^{\circ} / 8^{\circ}$ semestres, principalmente com relação à representação de vestuário odontológico adequado e à presença do paciente nos desenhos. Alguns princípios do projeto pedagógico podem estar sendo assimilados por uma porcentagem significativa de alunos, como questões de biossegurança e de prevenção. Outros métodos de avaliação do cumprimento dos objetivos pedagógicos precisam ser aplicados para confirmação desses sinalizadores de aprendizado explicitados neste trabalho.

\section{ABSTRACT}

The self-image of dentists: a study based on drawings made by undergraduate dental students

The aim of this study is to analyze the self-image of undergraduate dental students from the Braz Cubas University (BCU) in relation to the dental profession. In order to detect indicators as to the assimilation level of certain professional postures conveyed by the dental curriculum at BCU, students from the first and seventh/eighth semesters were asked to make drawings representing the dental professional profile sought by them. These drawings were classified and quantified according to the following criteria: scenery, dental instruments used, dental materials, clothes, presence of patient, rules of biosafety, the surfacing of emotions, and the pres- ence of words. Concepts of dental prevention were detected in the drawings of seventh/eighth semester students; the dental offices were well equipped in most of the drawings, characterizing successful carreers. Patients were rarely represented; when present, the depicted relationship between patient and professional was impersonal. It was concluded that the BCU students are learning principles of dental prevention, but the humanistic aspects need more attention.

\section{DESCRIPTORS}

Education, dental. Students, dental. Curriculum. Primary prevention, education.

\section{REFERÊNCIAS BIBLIOGRÁFICAS}

BOTTI, M. R. V.; SANTOS, G. M. C. Perspectiva do exercício profissional na Odontologia: Parte I - Análise sobre as expectativas e dificuldades dos formandos. $R G O$, v. 34 , n. 2 , p. 155-159, 1986.

CAMPOS, D. M. S. O teste do desenho como instrumento de diagnóstico da personalidade. 34. ed. Petrópolis : Vozes, 2002. 109 p.

CHAMBERS, D. W. The role of dentists in dentistry. J Dent Educ, v. 65 , n. 12, p. 1430-1440, 2001.

CORDON ART, B. V. M. C. Escher-the official website. Disponível em: http://www.mcescher.com/. Acesso em: 14/10/2003.

COX, M. Desenho da criança. 2. ed. São Paulo : Martins Fontes, 2001. p. 83-100.

CRUZ, A. C. S.; SILVA, E. M. C. Motivos para a escolha da carreira odontológica. Rev Odontol Univ São Paulo, v. 10, n. 4, p. 315-322, 1996.

HALLISSEY, J.; HANNIGAN, A.; RAY, N. Reasons for choosing dentistry as a career - a survey of dental students attending a dental school in Ireland during 1998-99. EurJ Dent Educ, v. 4, n. 2, p. 77-81, 2000.

McLEAN, M.; HENSON, Q.; HILES, L. The possible contribution of student drawings to evaluation in a new problem-based learning medical programme: a pilot study. Med Educ, v. 37, n. 10, p. 895-906, 2003.

SKELLY, A. M.; FLEMING, G. J. Perceptions of a dental career among successful applicants for dentistry compared with those of fifth-year dental students. Prim Dent Care, v. 9, n. 2, p. 41-46, 2002.

Aceito para publicação em 11/2003 